\title{
Children's Ward Development Foundation: a new programme for paediatric care in a rural community
}

\author{
Harris Pathirage ${ }^{1}$, L R Dissanayaka ${ }^{2}$, M D Herath ${ }^{2}$ \\ Sri Lanka Journal of Child Health, 2005; 34:50-1
}

(Key words: Children's ward development foundation)

\section{Background}

Care of the paediatric population in a rural area like Hambantota was a challenge. We had to face several hardships due to poor infrastructure of the health system, financial constraints preventing people from continuing care of their sick children and natural disasters occurring frequently in this area diverting attention away from health care.

The paediatric unit and special care baby unit (SCBU) functioned with several shortcomings. As the hospital is governed by a provincial council, it was not easy to fulfil even a minor requirement. Though we strived to overcome the hardships in this setup, it was mostly in vain. SCBU did not even have a glucometer or separate stethoscopes to examine premature babies. In many instances life-saving equipment did not work. Although the area was endemic for mosquito-borne diseases like malaria, dengue fever and encephalitis, there were only three mosquito nets to cater to a 45 -bed paediatric ward.

As the health care system of this provincial setup was badly affected by frequent trade union action, we had to face several problems in treating patients such as lack of drugs, inability to do investigations, cancellations of clinics and lack of transport facilities to transfer critically ill patients to nearby intensive care units. Majority of the people who lived in poverty were the victims of this situation. Parents could not afford the cost of medicine or investigations which were not available in the hospital or expenses for spectacles and hearing aids. Some parents could not afford the cost of milk foods for their malnourished children.

Children with congenital heart disease were put on long waiting lists in government hospitals for cardiac

${ }^{1}$ Consultant Paediatrician, ${ }^{2}$ Senior House Officer in Paediatrics, Base Hospital, Hambantota.

(Received on 30 September 2004)

surgery. Most parents could not afford to go to the private sector for surgery. Thus, these poor children were in and out of hospital till they died of complications like heart failure, pneumonia and pulmonary hypertension. We have experienced the tragedy of seeing these children dying on our hands on several occasions.

\section{Working plan}

Children's Ward Development Foundation (CWDF) was established in base Hospital, Hambantota in October 2002. This had 3 main objectives:

1. To fulfil the basic needs of the paediatric ward and neonatal unit.

2. To provide financial assistance to needy families.

3. Plan to overcome the delay for cardiac surgery in children with congenital heart disease.

A central committee of 11 members, presided over by the Consultant Paediatrician, was formed. The committee members included chief administrative and clinical personnel of the hospital and personalities from the area. The central committee was responsible for decision making and implementation of the programme. Children's ward development fund and heart surgery fund were formed separately from donations. Foundation was registered as a non-governmental social services association under the provincial council act. Children's ward development fund was utilized to fulfil the basic requirements of the ward and support poor patients and their families in various forms.

Paediatric cardiac surgery was planned at Sri Jayawardanapura General Hospital and two other private hospitals. Most of the expenses were borne by the heart surgery fund as patients received only $30 \%$ of the cost from President's fund. Patients were selected on the basis of urgency for cardiac surgery. All patients were followed up during the hospital stay 
for heart surgery and subsequently. Central committee had regular meetings quarterly and discussed the progress of the programme with the budget report for the particular period.

\section{Implementation of programme}

Children's ward development fund and heart surgery fund received donations up to 4 million rupees. The wide media support, locally and internationally, via web sites was a key factor behind the success of this programme. Within a one year period the following infrastructural developmental and social welfare work were implemented:

- The paediatric ward and neonatal unit were given a new look with renovation of water and electricity systems and colour washing of the wards. Most basic requirements like purchasing of glucometers, neonatal stethoscopes, mosquito nets, emergency care equipments etc. were fulfilled.

- $\quad$ Financial assistance scheme for under privileged families was implemented successfully. More than 100 families, identified from the ward and paediatric clinic, received benefits in terms of supply of medicines, expenses for investigations not available in the hospital, travelling expenses for regular clinic visits, supply of spectacles and hearing aids etc. In several instances, funds were utilised for fuel expenses for ambulances to send critically ill patients to nearby intensive care units.

- $\quad$ Seventeen children with congenital heart disease, who required urgent cardiac surgery, were operated on during the one year period. These comprised 4 children with ventricular septal defects (3 having pulmonary hypertension), 3 with patent ductus arteriosus ( 2 having pulmonary hypertension), 5 with tetralogy of Fallot, 2 with atrial septal defects and 3 with complex heart disease. 15 children recovered completely while 2 died from post operative complications ${ }^{1}$.

\section{Discussion}

Care of a sick child should not be confined to treating the medical condition but should also be extended to his emotional, psychological and social wellbeing. However, it was not possible to deliver basic healthcare to sick children in many instances due to major drawbacks in the healthcare system of this setup $^{2}$. CWDF was established in October 2002 in Base Hospital, Hambantota to face this challenge.

The main theme of the foundation was the "overall care of the sick child". In this respect we had to look into the social, psychological and financial problems of the family of a sick child. In the first instance, we had to work hard to fulfil the basic requirements of the paediatric ward and neonatal unit. At the same time, the financial assistance scheme was implemented. It was not possible to extend this scheme to all patients admitted to the paediatric unit. But this exercise was a model which would help to plan such a programme at a national or provincial level $^{3}$. Regular meetings of the central committee to assess progress, review budget, audit reports and accurate record keeping were the success behind this programme. Children's ward development fund and heart surgery fund received donations up to 4 million rupees. As the programme was implemented we realised it was possible to reach even a higher target, but it required the confidence of the people. We realised that this model can be implemented in other areas for the benefit of under privileged social groups in our community. We also highlight the need of a national programme to identify and carry out paediatic cardiac surgery to avoid untimely deaths of poor children ${ }^{4}$.

\section{References}

1. Daniel Bernstein. Cardiovascular system. In: Behrman R.E, Kliegman R M, Arvin AM, editors. Nelson Text book of Paediatrics. Bangalore. Philadelphia: W B Saunders 1996; 1262-330.

2. Ebrahim G J, Cutting W A M. Child health in developing countries. In: Campbell A.G.M, McIntosh Neil, editors. Forfar and Arneil Text Book of Paediatrics. London: Churchill Livingstone 1992; 1911-26.

3. Lee M Osborne. Cultural issues in Paediatric care. In: Behrman R E, Kliegman R M, Arvin A M, editors. Nelson Text book of Paediatrics. Philadelphia: W B Saunders 1996; 16-8.

4. Milner A D, Hull D. Hospital Paediatrics. 2nd ed. Edinburgh; Churchill Livingstone 1995. 
